\title{
Cigarettes with defective filters marketed for 40 years: what Philip Morris never told smokers
}

\author{
J L Pauly, A B Mepani, J D Lesses, K M Cummings, R J Streck
}

Tobacco Control 2002;11(Suppl I):i51-i61

Background: More than $90 \%$ of the cigarettes sold worldwide have a filter. Nearly all filters consist of a rod of numerous ( > 12 000) plastic-like cellulose acetate fibres. During high speed cigarette manufacturing procedures, fragments of cellulose acetate that form the mouthpiece of a filter rod become separated from the filter at the end face. The cut surface of the filter of nearly all cigarettes has these fragments. In smoking a cigarette in the usual manner, some of these fragments are released during puffing. In addition to the cellulose acetate fragments, carbon particles are released also from some cigarette brands that have a charcoal filter. Cigarettes with filters that release cellulose acetate or carbon particles during normal smoking conditions are defective.

Objective: Specific goals were to review systematically the writings of tobacco companies to: (a) identify papers that would document the existence of defective filters; (b) characterise the extent of the defect; (c) establish when the defect became known; (d) determine whether the defect exists on cigarettes marketed currently; (e) assess the prevalence of the defect on cigarettes manufactured by different companies; ( $f$ ) define whether the knowledge of the defect had been withheld by the tobacco company as confidential and not disclosed publicly; and (g) ascertain the feasibility of correcting or preventing the defect.

Methods: Document searches utilised databases of the scientific literature, medical journals, chemical abstracts, US Patents, Tobacco Abstracts, papers presented at tobacco meetings and court documents. Results: Sixty one documents of Philip Morris, Inc were selected for study because they disclosed specifically the "fall-out" of cellulose acetate filter fibres and, for cigarettes with charcoal filters, carbon particles from cigarette filters. The term "fall-out" was defined in 1985 laboratory protocols of Philip Morris, Inc. as "loose fibers (or particles) that are drawn out of the filter during puffing of the cigarette". As early as 1957, the health concern of inhaling cellulose acetate fibres released from cigarette filters was addressed by Philip Morris, Inc. A 1962 document reported the results of laboratory tests conducted by Phillip Morris, Inc that compared the "fall-out" of cellulose acetate fibres from the filters of their cigarettes (Marlboro) and cigarettes of their competitor (Liggett \& Meyers). A 1997 overview by Phillip Morris of documents addressing the "fallout of carbon particles and cellulose acetate fibers from filters" stated that they were "essentially routine reports" of cigarette filter assays, and referenced a "Filter Fallout" memo written in 1961 -more than 40 years ago. Most likely these tests are being conducted presently as illustrated by a 1999 report that details the revisions of the "fall-out" protocol of Phillip Morris, Inc and reports the results of tests that measured the discharge of cellulose acetate fibres and silica gel from beta cigarettes with a new type of filter. Our analysis of the "fall-out" tests results presented in the 61 "fall-out" documents showed that filter fibres and carbon particles were discharged from the filters of all types of cigarettes tested. These cigarette types ( $n=130$ ) included both coded cigarettes and popular brand name cigarettes. No publications were found in the scientific literature of the "fall-out" studies. Thus, the results of the "fall-out" studies are thought to have been withheld as confidential to Philip Morris, Inc. We have identified also other companies that have tested recently cigarettes for defective filters. In addition, our searches have shown that simple, expedient, and inexpensive technologies for decontaminating cigarette filters of loose cellulose acetate fibres and particles from the cut surface of the filter have been developed and described in 1997 and 1998 US patents. What is more important is that these patents also define methods for preventing or reducing the broken plasticlike fibres that arise during cigarette making. Many US patents ( $n=607 ; 1957$ to 2001) have been awarded for cigarette filters. Some of these inventions describe novel materials and unique filtration schemes that would eliminate or minimise the discharge of filter materials into mainstream smoke.

Conclusions: We have shown that: (a) the filter of today's cigarette is defective; (b) Philip Morris, Inc has known of this filter defect for more than 40 years; (c) the existence of this filter defect has been confirmed by others in independent studies; (d) many methods exist to prevent and correct the filter defect, but have not been implemented; and (e) results of investigations substantiating defective filters have been concealed from the smoker and the health community. The tobacco industry has been negligent in not performing toxicological examinations and other studies to assess the human health risks associated with regularly ingesting and inhaling non-degradable, toxin coated cellulose acetate fragments and carbon microparticles and possibly other components that are released from conventional cigarette filters during normal smoking. The rationale for harm assessment is supported by the results of consumer surveys that have shown that the ingestion or inhalation of cigarette filter fibres are a health concern to nearly all smokers. 
C igarettes marketed today may be perceived as having essentially two sections-a column of tobacco and a filcigarettes sold today in the USA and more than $90 \%$ of the cigarettes sold worldwide. ${ }^{1-10}$ Thus, the filter is an integral component of most cigarettes.

Historically, filters were introduced to provide a cigarette mouthpiece that would prevent the release of tobacco flakes into the smoker's mouth. In 1950, cigarettes with filters commanded but $1 \%$ of the market. Thereafter, filter cigarettes gained popularity. In 1964, the US Surgeon General announced that cigarette smoking is causally related to lung cancer in men. ${ }^{11}$ At about that time, the majority of cigarettes had filters $(64 \%, 1995)$. In 1986, 95\% of the cigarettes made in the US had filters. ${ }^{23}$ (table 1 ).

Viewing the white face of the cigarette filter with the naked eye and compression of the filter column with the fingers would suggest that the filter is made of a sponge-like material. However, opening the cigarette filter, by cutting it lengthwise with a razor, reveals that it consists of a fibrous mass. Spreading apart the matrix reveals some of the more than 12000 white fibres. Microscopically, these fibres are Y shaped and contain the delustrant titanium dioxide. The fibres are made of cellulose acetate, a synthetic plastic-like substance used commonly for photographic films. A plasticiser, triacetin (glycerol triacetate), is applied to bond the fibres. ${ }^{126-8}$

The speed at which cigarettes are made challenges the imagination - a single machine makes filter cigarettes at the rate of 15000 or more per minute. This figure of 15000 filter cigarettes per minute may be expressed also as 250 cigarettes per second; this is the equivalent of 50 cartons every 40 seconds. Likewise, cigarettes are boxed rapidlyapproximately 450 packs per minute. State-of-the-art production plants of major tobacco companies operate around the clock with multiple cigarette making and packing machines to produce millions of cigarettes daily.

During the high speed multi-step cigarette manufacturing procedures, cellulose acetate filter fragments break from the filter. Moreover, charcoal granules are released from cigarettes with certain types of charcoal filters. With a hand held magnifying glass, some of these black specks of charcoal are visible on the white filter face (table 1).

The definition of a defective filter has been presented previously. Specifically, in 1996 it has been established that for cigarettes with non-defective filters: "no charcoal particle enters the mouth of a smoker when he or she smokes." In contrast: "A defective filter cigarette to whose filter end face charcoal particles are exposed, or through which charcoal particles are seen must be removed from the manufacturing line." Accordingly: "a filter cigarette with a defective filter end face must be excluded because it is a defective product." ${ }^{12}$

Likewise, we know that: "fragments of plastic fibers, such as cellulose acetate fibers, forming part of mouthpieces of filter cigarettes or like rod-shaped smokers' products tend to become separated from the respective filter mouthpieces at the end faces which develop in response to the making of cuts across filter rod sections of double unit length between pairs of plain cigarettes to obtain filter cigarettes of unit length." It is emphasised that: "The fiber contamination of the mouthpiece occurs in spite of the partial bonding of the neighboring fibres to each other by resorting to suitable plasticizers." These quotations are from 1997 and 1998 US patents awarded to Hauni Maschinenbau AG. ${ }^{13}{ }^{14}$ Hauni AG, with its eight divisions of companies, has an established reputation as the world's top manufacturer of high speed machinery for making, packaging, and analysing cigarettes.

Cigarettes have defective filters if cellulose acetate filter fragments are released from the filter by puffing. In 1995, an executive directive declared that tobacco companies: "are well advised to strongly urge filter manufacturers to explore ways of producing fiber-free filters. Cellulose acetate fibers, in the smallest concentrations, must not be found in lungs. This is true even if there is little likelihood for their contributing to the formation of lung cancer and to disease type inflammatory changes." 15

These observations and writings from independent investigators have prompted us to undertake the studies reported herein. In these studies, we tested the hypothesis that different tobacco companies have known of defective cigarette filters for many years. Moreover, it is theorised that tobacco companies, alarmed by the potential human health risks, in addition to those known to be associated with cigarette smoke, have concealed their findings of defective filters from scientists and smokers.

\section{MATERIALS AND METHODS \\ Study goals}

The goals of this study were to review systematically the writings of the tobacco companies to: (a) establish if different tobacco companies knew about the filter defect; (b) document when the defect became known to the tobacco industry; (c) assess the prevalence of the filter defect on cigarettes manufactured by different companies; (d) define whether the knowledge of the defect had been withheld by the tobacco company as confidential, and not disclosed publicly; (e) determine whether the defect exists for cigarettes marketed today, and (f) ascertain the feasibility of correcting or preventing the identified defect.

\section{Methods}

Writings of the tobacco companies addressing defective filters were searched using popular databases, including: Medline, Chemical Abstracts, US patents (IBM Intellectual Property Network and Delphion), and court documents. Court documents included those that were among the estimated 33 million pages of tobacco industry documents that are now accessible through worldwide websites. ${ }^{16}$ Full text searches were performed for documents on different websites, including: (a) tobacco documents at www.tobaccodocuments.org that incorporates the following document sources: American Tobacco Company, Brown \& Williamson Tobacco Company, Council for Tobacco Research, Lorillard, Philip Morris, Inc, RJ Reynolds Tobacco Co, Tobacco Institute, new Lorillard, new Tobacco Institute, Philip Morris Advertisements, Bliley documents, Health Canada, Minnesota State Trial, and Roswell Park Cancer Institute; (b) tobacco industry documents from the US Centers for Disease Control at www.cdc.gov that incorporates the following document sources: Guildford-British American Tobacco documents, Minnesota Tobacco Document Depository, ${ }^{16}{ }^{17}$ and other depositories that are listed at this website; (c) tobacco document websites of different tobacco companies (for example, Philip Morris, Inc at www.pmdocs.com); and (d) documents from the court case of David Tijerina et al (plaintiffs) v Philip Morris, Inc, and Hoechst Celanese Corp (defendants). ${ }^{18}$ Some of the documents from the Tijerina case were provided to one of the authors (JLP) who served as an expert witness. Written approval for the use of the documents from the Tijerina case for this report was obtained from the trial attorney. ${ }^{19} 20$

A manual search was performed of the: (a) "Table of contents" and "Index" for all volumes (volumes 11-26) of Tobacco Abstracts published from 1967 to 1982 ( $\mathrm{n} \sim 33588$ abstracts), and (b) papers presented at annual congress of the Centre de Co-opération Pour Les Rescheres Science Relatives $\mathrm{Au}$ Tabac (CORESTA) from 1964 to 2000 (37 volumes), and from 17 special issues from different CORESTA symposia.

\section{RESULTS}

\section{Literature searches for defective filters}

Documents addressing cigarette filters were retrieved from different databases. A collection of Philip Morris, Inc 
Table 1 Chronology of events related to the marketing of cigarettes filters in the USA, and filter fibre and carbon particle "fall-out" assays of Phillip Morris, Inc

\begin{tabular}{|c|c|}
\hline Date & Milestones and documents \\
\hline 1860 & From 1860 to 1920 , cigarette filters were used to keep tobacco particles from entering the mouth ${ }^{1278}$ \\
\hline 1863 & Cigarette filters introduced with charcoal powder, cotton wool, flax, hemp, cloth or course paper 67 \\
\hline 1917 & Cigarette filters produced with crepe paper ${ }^{7}$ \\
\hline 1924 & Cigarette filters made by combining crepe paper and cellulose wadding ${ }^{7}$ \\
\hline 1931 & Parliament cigarettes (Benson \& Hedges) - first major filter tip cigarettes in USA ${ }^{67}$ \\
\hline 1936 & Viceroy cigarettes (Brown and Williamson)-the first filter cigarette at a popular price. Filter was of treated crepe paper ${ }^{67}$ \\
\hline 1949 & "Golden Throat" filter introduced by Rothmans, Int-cotton wool with crepe paper? \\
\hline 1950 & Until the 1950s, "tipped (filter) cigarettes were felt to be a novelty item directly mainly at the women's market" \\
\hline 1950 & Cigarettes with cellulose acetate filters introduced ( $1 \%$ market share); non-filter cigarettes $(99 \% \text { market share })^{2} 37$ \\
\hline 1950 & $\begin{array}{l}\text { Viceroy became the first serious brand to feature a filter made from cellulose acetate ("20,000 tiny filter traps"). By } 1953 \text {, Viceroy was } \\
\text { marketed as both regular and king size. The therapeutic qualities of the filter were hinted at in their advertisements } 7\end{array}$ \\
\hline 1952 & Kent "Micronite" cigarettes were introduced by Lorillard. Filter contained harmful crocidolite asbestos fibres. ${ }^{56} 104$ Filter with asbestos fil \\
\hline
\end{tabular}

1952

1954

1954 Parliament cigarettes with recessed filter introduced by Philip Morris, Inc $c^{6} 722$ removed from the market in 1954

1956 Kent cigarettes introduced by Lorillard with "Micronite" filter having "high filtration" cellulose acetate (Estron) ${ }^{6} 7$

1956 Cellulose acetate filaments made by Tennessee Eastman and Celanese companies treated with plasticisers ${ }^{7}{ }^{21}$

1957 Human health risks associated with the inhalation of cellulose acetate filter fibres discussed by the president of Phillip Morris, Inc and by officers of other US and European companies ${ }^{21}$

1958 Cellulose acetate fibres released from all filter cigarettes tested: Tareyton, Winston, Kent, L\&M, Marlboro, and Viceroy. Charcoal granules were discharged from the filter of Lark cigarettes. Study was funded by the Brown and Williamson Tobacco Co. ${ }^{106}$

1959 Food and Drug Research Laboratories report results to studies contracted by Phillip Morris, Inc to examine "five leading brands [Kent L\&M, Marlboro, Salem and Winston] of filter tipped cigarettes for the purpose of evaluating, qualitatively, the relative amounts of this particulate material which could be aspirated from the filters under conditions simulating normal smoking." 107108

"Filter fiber fall-out" studies initiated to count and size cellulose acetate fibres released during smoking (Phillip Morris, Inc ${ }^{24}$ )

"Carbon particle fall-out" studies initiated to count charcoal granules released from cigarettes with charcoal filters (Philip Morris, Inc ${ }^{26}{ }^{80}$ ). "All cigarette filters can be shown to transmit particles to the smoker. The [human lung] free passageways are a thousand times, yea ten thousand times, larger than particles which may pass through them. This goes for carbon, tobacco, sand, clay, lint [fibres, threads, cotton, cellulose] and all similar impurities." Memo to Mr Hugh Cullman (CEO, Philip Morris, Inc) from H Wakeham (director of research, Philip Morris, Inc) ${ }^{115}$

1962 Philip Morris, Inc reports results of cellulose acetate filter fibre "fall-out" tests that compared their leading brand cigarette (Marlboro) versus their competitor's leading cigarette (L\&M) ${ }^{24}$

1964 Surgeon General's report concludes that smoking causes lung cancer of men. Filter business becomes a health issue. Sales of filtered cigarettes increase remarkably ${ }^{2} 3611$

Carbon particles are released from Lark cigarettes with charcoal filters reported in "fall-out" studies of Phillip Morris, Inc 2831100101106114 Marlboro becomes the No. 1 cigarette brand worldwide ${ }^{6}$

Almost all cigarettes sold have filters (93\% market share; non-filter cigarettes, $7 \%$ market share $)^{2} 36$

1983 Cellulose acetate fibre and carbon granule "fall-out" studies of Philip Morris, Inc-of the documents available, the largest number for any one year were those of $1983^{55-68}$

Revised protocols for filter fibre fall-out (Method S-42) and carbon particle fall-out (method S-43) written by Philip Morris, Inc ${ }^{79} 80$

The largest number of US patents $(n=36)$ awarded for cigarette filters in any given year was in 1987

1992 Health risks associated with the inhalation of tar coated cigarette filter fibres are discussed for the first time in the popular press (Greensboro News and Record ${ }^{110}$ )

1993 Cellulose acetate fibres and particles released from cigarette filters is reported ${ }^{97}$

1993 Cigarette filter fibres identified in the lungs of patients with cancer is reported ${ }^{111}$

1993 R J Reynolds denies that cellulose acetate filter fibres are present in mainstream cigarette smoke 949596116

1994 Phillip Morris, Inc. submits order for active record disposal to Nancy Ryan, a technician performing cigarette filter fibre and carbon particle "fall-out" assays"

1995 Cellulose acetate fibres and particles released from the filters of popular US brand cigarettes is substantiated in studies using different standardised testing methods was reported by Pauly and co-workers; the question of harm is raised again ${ }^{98}$

1995 The filter of Kent Micronite cigarettes (Lorillard) are shown to release thousands of asbestos fibres and particles during normal smoking conditions. The questions of harm is posed ${ }^{6} 104$

Smokers (Tijerina et al) file suit against Philip Morris and Hoechst Celanese; defective product (cigarette) litigation ${ }^{18}$

1995

1995

1995

1997

Reemtsma, Inc reports that the observed filter fragments that exist on filter tip are not released into the smoke stream ${ }^{117}$

Social Science Research Council envisaged projects and defines costs to address findings of Pauly and co-workers ${ }^{118}$

Studies of human smokers show that charcoal granules are released from the charcoal filters of Lark cigarettes 100101

US patent No. 5,645,087 awarded to Hauni AG for "decontaminating" cigarette filters ${ }^{13}$

1998 State of Minnesota v. Philip Morris et al. Tobacco Companies required to surrender documents; Philip Morris releases some memos describing "fall-out" studies" 17

$1998 \quad$ Inhaled cellulosic and plastic fibres found in human lungs ${ }^{119}$

1998 Filters of novel cigarette appearing nicotine delivery devices are shown to be contaminated with glass fibres and particles (Premier, Eclipse and NEW Eclipse) $)^{102}$

1998 US patent No. 5,738,115 awarded to Hauni AG for "decontaminating" cigarette filters 14

1998 Borowicz and colleagues report results of tests in which cellulose acetate filter fibres and particles are recovered from mouth washes of all smokers and for all cigarettes tested ${ }^{99}$

Filtrona International Ltd reports the results of studies of fibre fragments from six different cigarette filter types released in tap tests; however, very few fibres found in sham smoking ${ }^{120}$

1999

1999

Philip Morris, Inc reports the release of cellulose acetate filter fibres in "fall-out" studies performed using a revised testing protocol ${ }^{88}$

Most recent filter fibre "fall-out" report available from Philip Morris, Inc ${ }^{88}$

1999 Eastman Chemical Co and others report the results of studies characterising cellulose acetate fibres released from the filter end of cigarettes $^{121} 122$ 2000 Fibres, particles, and other filter elements discharged from the filter into mainstream smoke identified as the "third phase" of cigarette
smoke

$2000 \quad$ Survey documents that most all smokers (>95\%) perceive that inhalation and/or ingestion of cellulose acetate filter fibres is an additional risk to that known to be associated with cigarette smoking and that tobacco companies have an obligation to inform smokers of this defect. Smokers believe that tobacco companies should advise smokers of filter defects ${ }^{93}$ 
documents was culled out that addressed the release of different substances from the cigarette filter. ${ }^{21-84}$ These documents are referenced chronologically.

\section{Philip Morris filter "fall-out" documents}

Of the papers identified in our literature search, 61 were identified as unique in that they were documents of Philip Morris, Inc that addressed the "fall-out" or "fallout" of filter fibres and carbon particles from the cigarette filter. ${ }^{24-84}$ The term "fall-out" or "fallout" appeared in all 61 documents. Further, one of these two terms appeared in $85 \%$ of the document titles $(52 / 61)$. The term "fall-out" was used in the title and text of the "FILTER FIBER FALL-OUT" protocol" ${ }^{79}$ and "CARBON PARTICLE FALL-OUT" protocol $^{80}$ of Philip Morris, Inc. We therefore designated this collection of 61 papers as the "Philip Morris Filter fall-out documents", and selected them for study.

All 61 papers were typed reports. Most were written on Philip Morris, Inc stationary as an interoffice correspondence $(\mathrm{n}=44 / 61 ; 72 \%)$. The majority $(\mathrm{n}=51 / 61 ; 84 \%)$ of these memos were one page long. The largest document was 11 pages. ${ }^{73}$ All documents were stamped with at least one Bates number. Some had more than one Bates number. Identical documents sometimes had different Bates numbers. ${ }^{35}{ }^{36}$ Some documents were stamped also with what is thought to be a central file code number of Phillip Morris, Inc (for example, C70-022269)..$^{30}$

Searches were made of these documents to identify named individuals and their employment position, cigarette brands smoked, frequency and number of fibres and particles released in the tests, additional laboratory protocols, toxicology studies, and assessments of human health risks.

The first document of Phillip Morris, Inc that addressed human health risks associated with the inhalation of filter fibres was written in $1957^{21}$ to the president, OP McComas. ${ }^{621}$ The letter discloses the concern for the potential dangers associated with the inhalation of cellulose acetate filter fibres, and specifically Tennessee Eastman's "Estron" type tow. Four years later, the results of filter fibre "fall-out" comparative tests of Marlboro and LEM were presented to $\mathrm{H}$ Wakeham (director, research and development, Philip Morris, Inc). ${ }^{61}$

Of this collection of 61 documents, most were written in 1983 ( $\mathrm{n}=11$ documents). Many documents were from adjacent years (1982, $\mathrm{n}=8$ documents; 1984, $\mathrm{n}=9$ documents)..$^{50-77}$

The purpose of all the memos was to report the results of tests measuring the "fall-out" of filter fibres and carbon granules. Two laboratory protocols ${ }^{79} 80$ and selected "fall-out" assay results for both cellulose acetate fibres and carbon particles are described below.

\section{Measurement of filter fibre "fall-out"}

A 1985 report entitled: "Filter fibre fall-out," authored by Nancy R Ryan, identifies "Method No. S-42" which is a protocol that describes the equipment and procedures used for assaying the "fall-out" of fibres from cigarette filters. ${ }^{79}$ The term "fall-out" was defined in this protocol as: "Loose fibres that are drawn out of the filter during puffing of the cigarette and collected on filter media are called filter fibre fall-out". ${ }^{79}$

Operationally: "cigarettes are smoked unlit with standard smoking machine operating parameters (Method S-2)" selected to mimic human smoking behaviour (for example, $35 \mathrm{ml}$ puff, 2 second duration). The Smoking Machine Protocol (Method S-2) could not be found in a database search of different tobacco documents. Each cigarettes tested was "drypuffed" (unlit) five times. The filter fibres released were trapped on a Millipore filter pad that had replaced the standard Cambridge glass fibre filter pad used commonly for assaying particles ("tar") in cigarette smoke. ${ }^{26879}$

The white Millipore ${ }^{\circledast}$ filter pad was "colored black prior to dry puffing" with a "felt ink marking pen," undoubtedly to facilitate viewing the white cellulose acetate fibres. According to the protocol, "The fibres, that had been trapped on the Millipore pads, were examined microscopically for number and size." The size of the fibres was sometimes reported as fibre length: $<50 \mu \mathrm{m}, 50-100 \mu \mathrm{m}, 110-200 \mu \mathrm{m}, 210-300 \mu \mathrm{m}, 310-$ $400 \mu \mathrm{m}, 410-500 \mu \mathrm{m}$, and $>500 \mu \mathrm{m} .^{79}$

We tabulated the cigarettes tested in the "fall-out" assays. A total of 130 cigarette types was identified, and these included coded and brand cigarettes. Most of the cigarettes were coded $(\mathrm{n}=116 / 130 ; 89 \%)$. We were unable to locate in our searches of different databases the key that would allow us to identify the different brands of the coded cigarettes. Popular cigarette brands $(n=14)$ included those of Philip Morris, Inc as well as cigarettes of its competitors. These cigarettes included: Avalon, Benson \& Hedges, Cambridge, Kent, L\&M, Lark, Marlboro, Merit, Montclair, Parliament, Salem, Winston, Saratoga, and Tareyton. The brand tested most frequently was Marlboro. For a given cigarette brand, different filter designs were thought to have been tested (for example, Marlboro KS-test and Marlboro KS-cont; see below) ${ }^{82}$

We have reviewed the test results presented in all of the "fall-out" documents. For all tests, filter fibres were released from all types of cigarettes tested.

The results of two filter fibre "fall-out" studies ${ }^{25}{ }^{82}$ have been selected for presentation as representative of the filter "fall-out" tests performed.

In the first study, a 1962 investigation entitled "Project \#8101" was conducted to measure the differences in the "fall-out" of "CA" (cellulose acetate ${ }^{85}$ ) fibres from 25 Marlboro and 25 LEM cigarettes. ${ }^{25}$ The LEM cigarettes released a total of 231 fibres whereas Marlboro cigarettes released 56 fibres. ${ }^{25}$

In reporting these results, it was noted that: "The fall-out particles from Marlboro are also smaller in length and diameter." The reader wishing to view the large number and diverse size of the filter fibres released in these "fall-out" assays may do so by retrieving the photographs in this report. ${ }^{25}$

The second study that we have selected to profile is a relatively recent (1995) project, entitled: "Background information on cigarette filter fibers release upon smoking." As was the intent of the previous study, this project compared the fall-out of fibres from different brands. Cigarettes tested included Marlboro KS-test, Marlboro KS-Cont, Marlboro 1002C1, Lark Special Lts 5D2, and Cambridge 100-1A1. In all assays, fibres were released from the filters. The total number of fibres released, from 10 cigarettes of each of the five types of cigarettes were: $37,36,30,20$, and 125 , respectively. ${ }^{82}$

\section{Measurement of carbon particle "fall-out"}

A 1985 document entitled "Carbon particle fall-out" authored by Nancy R Ryan, defines "Method No. S-43", which is a protocol that describes the equipment and procedures for assaying the "fall-out" of carbon particles release from cigarettes with charcoal filters. ${ }^{80}$ In this protocol, the term fall-out was defined as: "Loose particles that are drawn out of the filter during puffing and collected on filter media are called carbon particle "fall-out"." This carbon particle "fall-out" protocol S- $43^{80}$ shares many features (for example, authorship, date, goal, methods and equipment) as that of the protocol S-42 for filter fibre "fall-out". ${ }^{79}$

The purpose of protocol S-43 was to enumerate and size carbon particles that had been released from cigarettes with charcoal filters. The apparatus (for example, standard Philip Morris, Inc smoking machine) for testing and procedure is similar to that of the filter fibre "fall-out" protocol (Method No. S-42; see above). In all instances, they were performed using unlit cigarettes. Size range of the black particles was reported as: $<5 \mu \mathrm{m}, 5-10 \mu \mathrm{m}, 11-20 \mu \mathrm{m}, 21-30 \mu \mathrm{m}, 31-$ $40 \mu \mathrm{m}, 4 \mathrm{l}-50 \mu \mathrm{m}$, and $>50 \mu \mathrm{m} .^{80}$

Tests for the release of filter fibres and carbon particles have been conducted for 15 years before the two 1985 "fall-out" 
protocols. By way of example, in a 1969 experiment that included Lark, and which made reference also to Tareyton cigarettes, it was noted that: "Although several [carbon] particles were visible by the naked eye, a predominance of particles were visible only under magnification.." ${ }^{29}$ Thus, the particles contaminating the filter face were small, and many of the specks would surely "fall-out" into mainstream smoke during puffing.

Indeed, repetitive tests showed that carbon particles were released. In a 1970 test of: "Fallout of cigarette filter material" (10 cigarettes, 5 puffs) carbon particles were sized and enumerated. ${ }^{30}$ The results were as follows: size range $5 \mu \mathrm{m}$ ( $\mathrm{n}=20$ particles ), 6-10 $\mu \mathrm{m}(\mathrm{n}=38), 1 \mathrm{l}-20 \mu \mathrm{m}(\mathrm{n}=22)$, and 21-30 $\mu \mathrm{m}(\mathrm{n}=14)$, etc. A total of 124 carbon particles was recorded.

In the same year, 1970, Parliament cigarettes of Philip Morris, Inc $(80,85$, and $100 \mathrm{~mm}$ length) were tested. The Parliament cigarette was unique in that it had a $5 \mathrm{~mm}$ recessed charcoal filter. ${ }^{6722}$ The novel filter was designed to prevent the tongue from touching the filter face. ${ }^{622}$ However, tests revealed that the filter of Parliament cigarettes released carbon particles that ranged in size from $5-120 \mu \mathrm{m} .^{22}$

We reviewed the test results in all of carbon "fall-out" papers. This review showed that carbon particles were released from all cigarettes tested. Noteworthy is that, in some studies, the particles released from cigarette filters were described as: ". . .too numerous to count". . $^{568}$

\section{Filter fibre denier and morphology}

A 1986 document entitled "Denier per filament of cigarette filter fibres", signed by Nancy R Ryan, defined "Method No. F-13" which describes procedures for examining fibres (cellulose acetate cigarette filter) to define the shape and denier per filament. ${ }^{86}$ Other protocols and methods were referenced in this document, but could not be located (that is, "Method Number F-14" ${ }^{\prime 86}$ ). Another related protocol, "Method F-12" describes the paraffin embedding and preparation of fibres from cigarette filters. ${ }^{87}$ These documents illustrate in-house studies at Phillip Morris, Inc were performed for many years to characterise the shape and morphology of cigarette filter fibres, and to measure the release of the cellulose acetate fibres during normal smoking conditions.

\section{Personnel participating in the "fall-out" studies}

We generated an alphabetised listing of different individuals at Philip Morris, Inc who were named in the 61 "fall-out" documents (for example, "To", "From", "cc" or in the written text). After excluding those entries that appeared to be duplicates (for example, J Griffin and JH Griffin, Jr), approximately 135 individuals were identified. The frequency that a name was cited was then determined. In addition, an attempt was made to identify the employment title of those persons named most often.

Nancy Ryan was as identified in a 1981 document as a Laboratory Technician IV. ${ }^{88}$ She worked in the analytical laboratories of Philip Morris, Inc under the supervision of Dr Tom Osdene and, for a short time, under the direction of Dr William A Farone ${ }^{89}$ The "fall-out" documents as well as Dr Farone has identified Nancy Ryan as the individual who performed most of the filter fibre and carbon particle "fall-out" assays. Nancy Ryan wrote approximately three quarters $(75 \%$; $n=38 / 61)$ of the "fall-out" documents, and her name appeared in documents written over a 16 year period (1977 to 1993).

A partial listing of research executives of Philip Morris, Inc named in the inter-office communications included: O McComas (president); R Seligman and $\mathrm{H}$ Wakeman (vice presidents); W Farone and T Osdene (research directors). ${ }^{621-84} 89$ Further, by way of example, a 1983 correspondence addressing "fall-out" assays that had been conducted for a new type of filter had been distributed to 39 individuals, 15 of whom were addressed as "Dr". ${ }^{66}$ Thus, the results of the fall-out assays were broadcasted widely and for many years to senior scientists and corporate executives. ${ }^{89}$

William Farone, PhD, was employed by Philip Morris, Inc from 1976 to 1984, and served as the director of applied research from 1977 to 1984. Dr Farone is named in 18 of the 61 "fall-out" documents. Dr Farone is an expert in cigarette design and engineering. His is also a specialist in product research and marketing.

Dr Farone's recollection, a communication of 1997 that reviews the "fall-out" assay memos, and the time line of the "fall-out" assays confirm that the tests were performed routinely. ${ }^{84}{ }^{89}$ The most recent filter fibre "fall-out" test results that we obtained were those presented in a 1999 report. $^{84}$ Thus, the discharge of cellulose acetate filter fibres and carbon particles has been known for 42 years, and tested routinely in "fall-out" assays that have been conduced for 40 years by Philip Morris, Inc ${ }^{24-84}$ (table 1).

Dr Farone has acknowledged that Philip Morris, Inc was concerned as to the possible health risks associated with inhaling filter fibres and carbon particles. Dr Farone reported to us that a claim made by Philip Morris, Inc that the filter fibres were too big to get into the lung was based upon an aerodynamic diameter concept only, and emphasised that the concept was an unproven hypothesis. Some of the fibres that "fall-out" of the filter are likely to be deposited in the mouth and upper airways. However, given the known frequency with which most people smoke cigarettes, Dr Farone asserted that it is inevitable that some of the cellulose acetate fibres would be inhaled.

One of the primary objectives in applying a plasticiser is to bind the fibres. The plasticiser, however, is applied before the cigarette filter is cut and other cigarette manufacturing processes. Thus, the bonding agent may curtail but would not eliminate the formation nor the release of filter fibre fragments. Dr Farone noted also that the introduction of ventilation holes in the filter would increase the flow of air though the filter and, thereby, may increase the potential for release of broken fibres lying freely on the cut surface of the filter. ${ }^{89}$

\section{Document destruction at Philip Morris, Inc}

We recovered a document entitled "Notice of active records disposal" that was sent to Nancy R Ryan, "Cigarette testing, research \& development", on l February 1994 from Information Security (Central File), Philip Morris USA. In this confidential document, Ms Ryan was to "initial each line below to indicate that the appropriate records have been destroyed". Further, it stated: "you must attach an explanation for those records that are retained beyond their retention period." Documents that were initialled as having been destroyed included: "Projects", "Projects-Administrative", "Diaries", and other papers. This document request was signed by Nancy Ryan and dated 18 February $1994 .^{90}$

Document management and destruction for some companies are a routine part of business operations. However, the document destruction memo to Ms Ryan (1994) was issued soon after the 1993 published reports of our research documenting the release of fibres from cigarette filters (table l; also see below: "Filter contamination . . .", "Laboratory research . . .", and "Discussion"). While this may be coincidence, we note that this declaration was issued only once-our searches of different document web sites failed to locate document destruction declarations issued to Ms Ryan in the preceding or subsequent years.

Filter contamination not disclosed by Philip Morris, Inc Having established that Philip Morris, Inc knew for approximately 40 years that cigarette filters released cellulose acetate fibres and carbon particles, we undertook a search of the scientific literature to determine whether the results of these 
experiments had been reported. Our efforts included a search of publications referenced in Medline, PubMed, Tobacco Abstracts, Chemical Abstracts, and CORESTA papers and reports.

These and related attempts failed to locate a report disclosing any of the results of the "fall-out" studies. A search was made of the Tobacco Abstracts, an annual publication of papers addressing tobacco related topics. Of the approximately 33588 papers published (1967 to 1982; mean 2785 papers/ year), we identified 1591 papers discussing "cigarette filters". However, of these 1591 papers, none reported: (a) the discharge of filter fibres, including cellulose acetate fibres of conventional cigarettes and asbestos fibres found in the Kent Micronite cigarettes; (b) charcoal or carbon from cigarettes with charcoal filters; and (c) protocols or observations addressing the integrity or quality control issues of cigarette filters.

Also, there were no reports from Phillip Morris, Inc that addressed the release of fibres, carbon or other filter elements of the cigarette filters in any of the papers presented during the last 37 years at the CORESTA meetings or special symposia.

The absence of papers from Phillip Morris, Inc examining these issues is remarkable in light of the fact that nearly all cigarettes manufactured during the past two decades have a cellulose acetate filter.

\section{Laboratory research of filter "fall-out" contaminants}

Given the duration of the investigation of Philip Morris, Inc that characterise fibre "fall-out" of diverse cigarette brands, we anticipated acquiring the results of toxicology studies that assessed the health risks of inhaling and/or ingesting the tar coated filter fibres and carbon granules that had been released from the filter during smoking. Results of toxicology tests were not found in any of the "fall-out" documents.

Other writings of Philip Morris, Inc that addressed cigarette filter fibres made reference to "ciliotoxicity", "saliva test", and other assays. One document entitled: "Review of cigarette product development program" addresses: "superior pulmonary clearance", "low carcinogenic index", "mucus flow method", "Iverson test", and "Physiological evaluation". ${ }^{91}$

Our search of multiple databases failed to locate documents presenting the results of toxicology studies of fibres and particles that are known to be discharged from cigarette filers during normal smoking conditions. At a minimum, we expected to find laboratory notebooks or at least photocopies of selected notebook pages. Not a single page was found.

\section{US patents for improved filters}

A search of US patents was undertaken to identify inventions that would prevent and/or reduce the discharge of filter elements into the mouth of smokers. The search retrieved 607 US patents that had been awarded for cigarette filters from 1971 to 2001 (mean (SD) $\mathrm{n}=19.58$ (7.07) patents/year; median $=19$ ). The largest number of US patents awarded for cigarette filters in any given year was 36 ; these patents were awarded in 1987.

Many patents described inventions for improving cigarette filters. Some of the discoveries were for: (a) various cigarette smoke purifying materials (for example, diverse fibre types, surface modified fibres, woven fibres, mesh material, open cell sponge items, solid porous structures, and granular materials; (b) various filter designs (for example, compound and multiple section filters); (c) filter ventilation (for example, increased air flow; reduction of cigarette smoke tar and gases); (d) selective elimination of specific toxins in mainstream smoke (for example, polycyclic aromatic hydrocarbons (PAH); and (e) delivering smoke modifiers (for example, flavourings and humectants).

Two US patents have been awarded to Hauni Maschinenbau AG for different methods and apparatus for decontaminating the exposed surfaces of filter mouthpieces in smokers' products. Methods used to "decontaminate" the cellulose acetate fibres from the filter mouthpiece were: (a) pneumatic systems, including the use of suction chambers; (b) electrostatic precipitation; (c) application of smoke permeable layers of filter material to overlie the end faces of the mouthpieces; and $(\mathrm{d})$ a bonding procedure in which some of the loose fibres would be affixed to the mouthpiece with a solvent or with the application of heat to the cut surface of the mouthpiece..$^{14}$

Preventive measures could be employed that would reduce the formation of broken and loose filter fibres during cigarette manufacturing including the use of heat or lasers to cut the filters. In effect: "the invention is to provide a simple, reliable and inexpensive method of preventing uncontrolled or random separation of fibers and/or fragments of fibers of filter material from filter mouthpieces". ${ }^{13}{ }^{14}$

Also noted in these two patents is that in the manufacturing of cigarettes, considerable quantities of "fragmentised" tobacco particles are collected and reintroduced into cigarette making machines. Both patents declare that: "This is not advisable as the cellulose acetate fibres would be placed in the tobacco column." The cellulose acetate fibres in the tobacco column are burned and would emit additional toxins into mainstream smoke.

We undertook a search of various databases to locate documents of Philip Morris, Inc that addressed their efforts, or discussions with manufacturers of cigarette machines, to rectify the filter fibre and charcoal particle "fall-out". No documents were found.

\section{DISCUSSION}

The cigarette filter studies reported herein have focused on the research conducted by Phillip Morris, Inc because: (a) the unique "fall-out" papers provided the largest collection of documents from any single tobacco company that address the release of cigarette filters fibres and particles; (b) the research described in the "fall-out" studies extended for four decades during which time cigarette design had changed considerably and the health risks of smoking had been more fully delineated; (c) the analytical laboratories of the world's largest tobacco company are perceived as having the best resources to undertake studies of defective filters (for example, funding, personnel, technology, and equipment); and (d) the mass cigarette production facilities would presuppose frequent collaboration, partnerships, and contracts with manufacturers of filter fibres (for example, "tow"), machines for making filter rods, plasticisers, and other items.

The term "fall-out", coined by Philip Morris, Inc, depicts the ease with which the loose fibres and particles are puffed from the cut surface of the cigarette filter. Collectively, the 61 "fallout" papers establish that cellulose acetate fibres and carbon particles are emitted from the filters of all cigarettes tested over a period of many years and under normal smoking conditions. Moreover, the filter defect is universal and widespread, and it is not restricted to a given cigarette brand, filter type or tobacco company.

Notwithstanding, the "fall-out" assay used is perceived as having many shortcomings which, if rectified, would demonstrate that more particles and fibres are released from the cigarette filter. For example, the cigarettes tested were never lit. As early as 1963 it was noted that: "This (unlit draw method), however, does not give us any information on the amount of carbon fall out to be expected when these cigarettes are smoked in the normal manner". ${ }^{26}$ Thus, it would be reasonable to expect that more carbon particles or cellulose acetate fibres would be released if lit cigarettes had been tested.

Filter fibre fall-out and carbon fall-out protocols stated that five puffs were collected for each cigarette. This is significantly 
lower than the 8-10 puffs that are prescribed in standard cigarette smoking procedures. ${ }^{258}$

Painting the Millipore filter used to capture the discharged filter elements with a black felt tip marker may occlude some of the micropores $(0.8 \mu \mathrm{m})$ of the membrane. Plugging the holes would reduce air flow and impair filtration. Additionally, the organic solvent of the ink may react adversely with the filter membrane. Ironically, the painting procedure was unnecessary because black micropore membranes similar to the white ones used by Phillip Morris, Inc have been available from Millipore for many years. Philip Morris, Inc, however, continued to use the membrane painting practice until 1999 at which time the assay protocol was revised. ${ }^{84}$

In standardised tests for measuring "tar" and mainstream components, the cigarettes are affixed horizontally to the smoking machine; this is the position that cigarettes are normally puffed by smokers. However, in the "fall-out" assay, the cigarettes are placed in a "vertical position through the use of a right angle glass tube on a standard smoking machine". Smokers place the face of the filter directly within the mouth and seal the cigarette with the lips. The filter is not compressed into a long glass tube. It would be anticipated that the length, curvature, air flow, and negative surface charge of the glass tubing would reduce the number of filter elements found on the assay membrane. Also, in contrast to a smoker, none of the filter vents were blocked in the "fall-out" assay. ${ }^{92}$ The cigarettes tested were "dry-puffed" (that is, not ignited). Thus, the test cigarettes were not "smoked". This represents yet another departure from normal human smoking conditions.

These issues raise questions as to whether a conventional smoking machine used routinely in collecting "tar" for chemical tests is a suitable surrogate for human smokers. ${ }^{8}$ Do the complex, multi-port machines provide an accurate instrument to be used in tests to identify, quantify, and size cellulose acetate filter fragments, carbon particles, crystals (for example, plasticiser), and other components from the filter that enter the smoker's mouth?

Another criticism is that "fall-out" assays were not performed with cigarettes that had been carried by smokers. Cigarettes from partially filled packs are jostled, sometimes vigorously, during daily transport. It would be reasonable to expect that the filters of these cigarettes would have more, and a greater diversity of, contaminants that lay loosely on the filter face. Some of the pollutants may arise from the heterogenous dregs present in the bottom of the pack. Extraneous debris may also drop into open "soft" packs and further contaminate the filter face.

The "fall-out" protocol contained no instructions for using reference cigarettes. Moreover, none of the test results gave values for the "fall-out" of filter fibres from reference cigarettes. Thus, the assays were thought to have been performed without reference cigarettes. Furthermore, tests were performed in duplicate which is inadequate for statistical analysis. Moreover, the reproducibility and fidelity of the "fall-out" assay was not determined. The smallest size classification of the fibres released from the filters assayed was "<50 microns". Thus, no attempt was made to count and classify small fibre fragments and fibre particles. These and other criticisms document that the experimental design was flawed in the "fall-out" studies of Philip Morris, Inc.

The question arises as to why the "fall-out" assays were conducted. The carbon particles on the filter face are not readily visible to the naked eye. Likewise, loose filter fragments are not apparent. Thus, these filter defects would not be seen by the smoker. In fact, a recent study has found that most smokers are unaware of the filter fibre "fall-out". ${ }^{93}$ Accordingly, the "fall-out" tests do not address an ugly cosmetic flaw.

The released fibre fragments would not be indicators of a change in the structural integrity of the filter. There is no basis to conclude that the observed release of filter fragments would result in the collapse of the filter plug that is composed of thousands of bonded long fibres. Further, there is no evidence that the discharged loose filter fragment or carbon particles would reflect a significant reduction in filtration efficacy. These and other conjectures permit the reviewer with no alternative than to conclude that the intent of the "fall-out" tests were to address harm.

We searched different databases to determine if companies other than Philip Morris, Inc were aware of the cigarette filter defect. Our findings showed that several other companies have recently investigated the release of cellulose acetate filter fibres. Variable results have been reported (table 1). This may be attributed to inappropriate methodologies or inexperience. In this respect, it is noted that no standardised testing procedures have been adopted.

Notable is that none of the companies who have reported studies that have been undertaken to measure the release of fibres from cigarette filters have made reference to the extensive "fall-out" studies of Philip Morris, Inc. Has Phillip Morris, Inc been successful in hiding their observations from other companies for several decades?

In 1993, the RJ Reynolds Tobacco Company (RJR) argued, albeit unconvincingly, that cigarette fibres are not released from cigarettes ${ }^{94}{ }^{95}$ (table 1). RJR cites a paper by Langer and colleagues, ${ }^{96}$ presented at a 1988 conference on cigarette smoke sponsored by RJR, and concludes that: "It has been shown in very rigorous analyzes that the mainstream smoke of modern cigarettes does not contain any fibrous material., ${ }^{94}$ To be noted, however, is that Langer and colleagues were studying inorganic particles in the cigarette ash and smokethey did not measure the release of filter fibres. In their studies, inorganic particles were collected onto a Millipore filter of mixed esters of cellulose acetate similar to those used by Philip Morris, Inc in the "fall-out" assays. To assay the captured inorganic particles, Langer dissolved the Millipore cellulose acetate membrane with acetone. Acetone would have dissolved the filter fibres because cellulose acetate cigarette filter fibres have a chemical composition similar to that of the filtration membrane. Thus, no cigarette filter fibres could be detected using the assay employed.

Before learning of the "fall-out" studies of Phillip Morris, Inc, we published the results of comprehensive tests documenting that cellulose acetate filter fibres were released from modern day cigarettes. Specifically, filter fibres were released from 12 different US cigarette brands; two brands from each of six different US companies. All cigarettes tested were purchased from local vendors. ${ }^{97}{ }^{98}$ Cellulose acetate filter fibres were implanted in mice for six months. The fibres withstood degradation and retained the tobacco brown colour and bright fluorescence of the tobacco tar that had been adsorbed from cigarette smoke. We reported also the presence of cellulose acetate cigarette filter fibres in human lung tissue. In his critique of this study, tobacco spokesperson Professor Dr F Adlkofer noted that: "With high probability, the fibres which were seen by the authors in the lungs of smokers with lung cancer are in fact cellulose acetate fibres." ${ }^{15}$

Results of studies presented in this report have been confirmed and extended in investigations of consenting adult smokers. The participant smoked a popular US filter cigarette in his/her usual manner, but was instructed not to inhale the smoke. Mouth washes of water were collected before smoking, at different intervals during smoking, and after smoking. The results showed that washes collected from all subjects and for all cigarettes smoked contained cellulose acetate cigarette filter fibres (range 2-25 fibres). In contrast, mouth washes obtained before smoking had no fibres. Notable is that most of the filter fibres harvested from the mouth were coated with tobacco tar. ${ }^{99}$

In experiments on Lark cigarettes that have a charcoal filter, we showed that carbon granules are released from nearly all of the cigarettes. This was thought to be caused primarily by the discharge of charcoal granules from the central cavity of the 
filter. The release of filter fibres and charcoal granules from Lark cigarettes was confirmed also in experiments using smokers ${ }^{100}{ }^{101}$; see also particle "filter particle fall-out" references. . $^{28} 3132-4750$ 51 53-64 $6870-7277$

We have discovered that glass fibres and glass particles contaminate the filters of Eclipse and Premier; these are cigarette appearing, low smoke, "reduced risk" products of RJR. ${ }^{102} 103$

Others have shown that "African blue" crocidolite asbestos fibres were discharged in large numbers $(n>100000$ in the first puff) from Kent Micronite cigarettes. These cigarettes were introduced in 1952 by the Lorillard Tobacco Company, and the filters were withdrawn from the market in $1956 .{ }^{6}{ }^{104}$

Collectively, our investigations have identified diverse types defective filters. These include filters that discharge various filter elements, including fibres (for example, cellulose acetate, glass and asbestos) and particles (for example, charcoal).

It is known commonly that cigarette smoke is a complex aerosol consisting of a particulate phase ("tar") and vapour or gaseous phase (for example, carbon monoxide). Components in these two phases arise from the pyrolysis or burning of the tobacco, and are assayed routinely. Another phase of cigarette smoke has been identified. This third phase is unique in that it does not arise as a result of tobacco pyrolysis. The third phase is the diverse material of the filter that is released from the filter during smoking. This newly defined phase of cigarette smoke must be characterised for content and dose, and with the same rigour used in prior toxicological tests of the tar and vapour phases. ${ }^{105}$

Concern of the health risks associated with the inhalation of cellulose fibres from cigarette filters was discussed in the late $1950 \mathrm{~s}^{21}{ }^{106}$ One example is that of a memo written more than 44 years ago to O P McComas, the president of Philip Morris, Inc. ${ }^{21}$ The letter reports in detail discussions among senior officers of many prominent companies of the cigarette industry (for example, Philip Morris, Inc, American Tobacco Company, Imperial Tobacco Company, and Reemstma), and manufacturers' of cigarette filter material ("tow"; Baumgartner, Tennessee Eastman, "Rochester Laboratories" [presumably Kodak]) and cigarette making machines (Molins). An excerpt from this letter reads:

\footnotetext{
"He wanted to know whether or not we had heard the rumors regarding the dangers of using Tennessee Eastman's Estron CA [CA, cellulose acetate ${ }^{85}$ ] type tow in filter cigarettes. He said when an Estron type plug is cut on a making machine, there always remains a few loose, hard particles of filament. These loose hard pieces of material are then sucked down into the lungs of the smoker and are considered to be capable of producing silicosis." 21
}

Two years later, in 1959, the Food and Drug Research Laboratories presented the results of studies that were contracted by Philip Morris, Inc. These tests showed that fibres and fine particulate matter were puffed from the filters of all cigarettes tested, and under conditions simulating normal smoking. The cigarette brands tested (Kent, L\&M, Marlboro, Salem, and Winston) were purchased from stores in different boroughs of New York. ${ }^{107} 108$

Also notable is a comprehensive 131 page report of 1959 that showed that cigarette filter filaments and charcoal granules were released from all popular filter cigarettes studied (Camel, Chesterfeld, Kent, L\&M, Lucky Strike, Marlboro, Philip Morris, Tareyton, Winston, and Viceroy). These studies were funded by the Brown and Williamson Tobacco Company. ${ }^{106}$

A recent study has assessed consumers' knowledge and beliefs about the safety of cigarette filters. In this survey, participants were asked: "If cigarette fibres become loose, and the

\section{What this paper adds}

Almost all cigarettes sold worldwide have a filter; thus, the filter is an integral part of today's cigarette. Furthermore, most filters are made of a cylindrical rod or plug that consists of thousands of plastic-like cellulose acetate fibres. We, however, do not know what studies have been conducted by the tobacco companies to: (a) address filter defects that may arise during cigarette manufacturing whereby loose debris of different forms (for example, fibres, fragments, particles, crystals, and fines) contaminates the cut surface of the filter and is released during normal puffing; and (b) assess the toxicology and human health risks of these diverse filter elements that are discharged into mainstream smoke.

This paper discloses that Philip Morris, Inc has known and concealed for approximately 40 years that fibres and particles "fall-out" of the filter of cigarettes during smoking. Other companies have assessed also the discharge of filter fibres. In addressing this filter defect, the tobacco industry's response has been variable, ranging from denial of the discharge of filter fibres to the development of innovative technologies for correcting and preventing the problem. Consumers have not been informed of the filter defect. Further, there is no indication that existing corrective technologies and invention have been uniformly implemented. Summarily, the tobacco industry has been: (a) derelict in concealing information of filter defects; (b) negligent in implementing technologies available to prevent or reduce the emission of filter elements; and (c) wrongful in not investigating the toxicology and harm associated with defective filters of today's cigarettes that are being marketed worldwide.

cigarette companies are aware of this, do you think that they have an obligation to warn the public about this?" All smokers and former smokers in this survey responded "yes". ${ }^{93}$

Also, the participants were asked: "If cigarette filter fibres are inhaled into the lung or eaten, would you consider this an additional health risks beyond the exposure to tobacco smoke?" Of current smokers surveyed, 90\% responded "yes". Of former smokers, 96\% responded "yes". Of significance was the fact that the panel members responded that they perceived that the filter fibres that had been "eaten" imposed a health risk beyond the exposure to tobacco smoke. ${ }^{93}$

Philip Morris, Inc has also performed field tests for which panel members have compared the filters on experimental cigarettes with filters of brand cigarettes (for example, Virginia Slims, Winston, Benson \& Hedges, Marlboro, and Premier). By way of example, in 1988, Philip Morris, Inc conducted a study of 74 one-on-one interviews and five focus groups illustrated that smokers expressed a contemptuous reaction to the "fiberglass" used in RJR's Premier. Some panellists were quoted by Philip Morris, Inc for being fearful of the health risks of inhaling the glass fibres. The issue of the health risks associated with the inhalation of plastic-like cellulose acetate filter may have been addressed, but the results have not been disclosed. ${ }^{109}$

In undertaking this review of industry documents on the subject of filter fibre "fall-out" we expected to locate laboratory reports of studies that been performed in-house or subcontracted to other laboratories including those outside the USA (for example, INBIFO, Hamburg, Germany). It had been anticipated that there would be documents that addressed the toxicity of the filter fibres and charcoal in studies of: (a) mutagenicity (for example, Ames test), (b) chromosomal alteration (for example, sister chromatid exchange (SCE); (c) cytotoxicity (for example, ex vivo) studies using human lung target cells such as human lung epithelial cells, lung fibroblasts, and lung macrophages; (d) inhalation 
toxicology (for example, lung deposition, retention, and pathology) of size specific cellulose acetate fragments and charcoal microparticles; and (e) smoke derived toxins adsorbed onto the surface of the cellulose acetate fibres and carbon granules. ${ }^{3-6}$ With but only two exceptions, the two 1959 laboratory reports discussed above, ${ }^{107} 108$ we failed also to find any communications from Phillip Morris, Inc to other cigarette companies, suppliers of filter materials, or laboratories that had been subcontracted to do research. We found no documents. Why?

The apparent destruction of relevant documents relating to this research is suspicious for its timing with reference to litigation of cigarettes as defective products $^{18}$ and our findings ${ }^{9798} 110{ }^{111}$ (table 1). This may account for the scant amount of research data found in the discovery process. ${ }^{112}$ Also, only a few of the 61 Philip Morris "fall-out" documents were found on the tobacco industry's web sites; approximately half of the documents were compiled from the Tijerina case. ${ }^{18}$ This is inconsistent with the promise by Philip Morris, Inc to consumers and members of the scientific and medical communities to share research on smoking and health issues. ${ }^{113}$

Inhalation by conscious and vigorous puffing of smoke from a cigarette by a nicotine addicted smoker is unlike the inhalation by unconscious shallow normal breathing. Ostensibly, the probability of inhaling fibres and particles from the two forms of inhalation is different. Would it not seem reasonable to theorise that fibre fragments and carbon particles would be inhaled from the filter by a smoker who places a cigarette to the mouth, seals the cigarette with the lips, and drags a bolus of $35-55 \mathrm{ml}$ of smoke deep into the lung? Many smokers repeat this exercise 200-400 times daily, and each day of the year. Thus, existing paradigms defining the dynamics of inhaled airborne pollutants cannot be applied to the inhalation of debris sucked from cigarette filters.

Fibres and particles that "fall-out" of the filter fill will be ingested and serve as a solid phase matrix for delivering adsorbed tobacco tar throughout the gastrointestinal tract. Could the fibres and particles released from the cigarette filter serve as aetiological agents or confounders for pathologies of the gastrointestinal tract?

Tobacco companies bare the burden of performing the toxicology studies necessary to assess the human health risks of the defective filters and, specifically, the dangers associated with the daily inhalation and ingestion of the substances discharged from the filter during normal smoking. All consumers, including smokers, have the right to be fully informed of product defects and the potential risks that they impose so that they can make an educated decision in selecting their cigarette purchases.

The inhalation and/or ingestion of toxin coated plastic fibres and carbon granules released from contaminated and defective filters is not intended to be part of the smoking experience. The filter is intended to reduce exposure to cigarette smoke toxins-any elements from the cigarette filter that are likely to be puffed into the lung must be recognised as pollutants. For a company to knowingly and willfully withhold this information from consumers about the known contamination of cigarette filters, as Philip Morris, Inc had done in the past and continues to do even today, is wrong.

In summary, our work documents that Philip Morris, Inc has:

(a) known for more than approximately 40 years that filters of popular US cigarettes release filter fibres and charcoal particles during smoking;

(b) established protocols for assaying the "fall-out" of filter fibres and charcoal granules;

(c) utilised these protocols routinely to count and size filter fibres and charcoal particles that are released from a filter; (d) undertaken comparative studies assessing the "fall-out" of filter fibres and carbon granules from their cigarettes and those of their competitors;

(e) continued the "fall-out" studies until 1999;

(f) known of the potential health risks associated with the "fall-out" of fibres and particles from the filter;

(g) understood that the discharged filter elements were likely to have adsorbed diverse toxins from the cigarette smoke;

(h) not disclosed the findings of the filter fibre "fall-out" and carbon granule "fall-out" to individuals who smoked their filter cigarettes as well as to scientists, physicians, public health officers, regulatory authorities, and others.

An additional 36 memos with carbon or fibre or filter and "fallout" in the title have been identified from documents of the central file of Philip Morris USA (confidential). Bates No. 2060531293-2060531309.

\section{ACKNOWLEDGMENTS}

The authors wish to acknowledge the assistance of literature retrieval and database searches by different personnel at the Roswell Park Cancer Institute, including Ms Gayle Ablove, Senior Medical Librarian, and Mr Craig Steger, Cancer Prevention, Epidemiology Biostatistics. We wish also to thank Dr WA Farone, who served from 1977 to 1984 as the Director of Applied Research at Philip Morris, Inc, for sharing with us his knowledge of the "fall-out" studies and issues related to cigarette design. Likewise, we are particularly indebted to Dr Dietrich Hoffmann, Associate Director, American Health Foundation, for the many hours that he devoted in assisting us.

Supported in part by NIH grants CA-16056, CA-67827, CA-77021-03, CA-97696-01 and Roswell Park Cancer Center Support Grant P30 CA 16056 from the US Public Health Services, and grant 03754 from the Robert Wood Johnson Foundation.

\section{Authors' affiliations}

J L Pauly, J D Lesses, R J Streck, Department of Immunology, Roswell Park Cancer Institute, New York State Department of Health, Buffalo, New York 14263, USA

K M Cummings, Department of Cancer Prevention, Epidemiology \& Biostatistics, Roswell Park Cancer Institute

A B Mepani, Cornell University, School of Arts and Sciences, Ithaca, New York 14850, USA

\section{REFERENCES}

1 Bednarczyk NE. Tobacco smoke filters. Park Ridge, New Jersey: Noyes Data Corp, 1972:1-263

2 Browne CL. The design of cigarettes, 3rd ed. Charlotte, North Carolina: Filter Products Division, Hoechst Celanese Corp, 1990: 119 pages.

3 Hoffmann D, Djordjevic MV, Brunnemann KD. Changes in cigarette design and composition over time and how they influence the yields of smoke constituents. J Smoking-Related Disorders 1995;6:9-23.

4 Hoffmann D, Hoffmann I, El-Bayoumy K. A less harmful cigarette: a controversial issue. Chem Res Toxicol 2001;14:767-90.

5 Institute of Medicine. Clearing the smoke: assessing the science base for tobacco harm reduction. Washington DC: National Academy Press, 2000:315 pages.

6 Kluger R. Ashes to ashes: America's hundred-year cigarette war, the public health, and the unabashed triumph of Philip Morris. New York: Alfred A Knopf, 1996:807 pages.

7 Memo to Dr Larry Sykes from Pat Walford. March 9, 1979 "Cigarette Filter Development." Bates No. 2021601017 - 2021601023

8 Norman A. Cigarette manufacture: cigarette design and materials. In: Davis DL, Nielsen MT. Tobacco - production, chemistry and technology. Oxford: Blackwell Science, 353-87.

9 US Department of Health and Human Services. The health consequences of smoking: the changing cigarette. A report of the Surgeon General, 1981. Rockville, Maryland: Public Health Service, Office of the Assistant Secretary for Health, Office on Smoking and Health, 1981:43. (DHHS Publication No (PHS) 81-50156.)

10 Wynder EL, Hoffmann D. Smoking and lung cancer: scientific challenges and opportunities. Cancer Res 1994;54:5284-95.

11 US Department of Health, Education, and Welfare. Smoking and health. Report of the Advisory Committee to the Surgeon General of the Public Health Service. Washington, DC: Public Health Service, 1964. (PHS Publication No. 1103. )

12 Matsumura T, Muramoto H, Komori M. US patent 5,583,633. Device for detecting a defect in charcoal type filters of manufactured filter cigarettes. December 10, 1996. 
13 Fidausia C, Fietkau S, Arnold P-F, et al. US patent 5,645,087. Method of and apparatus for decontaminating the exposed surfaces of filter mouthpieces in smoker's products. July 8, 1997

14 Fidausia C, Fietkau S, Arnold P-F, et al. US patent 5,738, 115. Method of and apparatus for decontaminating the exposed surfaces of filter mouthpieces in smoker's products. April 14, 1998.

15 Adlkofer, F. Report addressing: Fibers from cigarette filters: an additional risk for smokers? (Pauly et al, Cancer Research 1995;55:253-8). Febuary 25, 1995. Bates No. 20579926062057992607

16 Malone RE, Balbach ED. Tobacco industry documents: treasure trove or quagmire? Tobacco Control 2000;9:334-8

17 State of Minnesota and Blue Cross and Blue Shield of Minnesota v Philip Morris, R. J. Reynolds, Brown and Williamson Tobacco Co., BAT Industries, Lorillard Tobacco Company, The American Tobacco Company, Liggett Group, Inc., The CTR-USA, Inc. \& The Tobacco Institutes. State of Minnesota, District Court of Ramsey, Second Judicial District, File No. C1-94-8565. August 17, 1994

18 David Tijerina et al. (Plaintiffs) v Philip Morris, Inc., and Hoechst Celanese Corp. (Defendants); Civil Case No. 2-95-CV-120, 1996, In the United States District Court, For the Northern District of Texas, Amarillo Division.

19 Letter to John L Pauly from T. L. Cubbage II. Feb. 13, 1997. "Tijerina v. Philip Morris Inc. et al, No. 2:95-CV-120-j." I page.

20 Letter to John L Pauly from Tom Cubbage. Jul. 5, 2001. "Filter Fiber Documents." 3 pages.

21 Memo to Mr OP McComas from Anne C Stubing. May 1, 1957. (no title). Bates No. $2040015018-2040015020$

22 Press release from John Scott Fones. September 28, 1959. "Tests show recessed filter advantages - research executive discloses - series of panel tests just completed in Richmond." Bates No. $2021621611-2021621614$

23 Author and recipient not known. "Microscopically determine the amount (if any) of activated carbon coming thru the smoke of cigarettes with acetate tow filters $71 / 2 \mathrm{~mm} \mathrm{35 \%} \mathrm{KD} \mathrm{carbon} \mathrm{\# 20} \mathrm{paper} \mathrm{filler} \mathrm{next} \mathrm{to}$ the Tobacco"[C59-0260??; 69]." (cited in reference 25; Phillip Morris memo not available to authors). June 1, 1959

24 Memo to Dr RH Blackmore from H Wakeham. October 26, 1961. "Filter Fallout." Bates No. 1000862440.

25 Memo to Dr RH Blackmore from FE Van Nostran. January 15, 1962. "Demonstration of differences in 'fall-out' from Marlboro and L \& $M$ Filters." Project \#8101. Bates No. 1001886066-1001886068.

26 Memo to VC Johnson from Mr TE Resnik. September 25, 1963. "Carbon particle fall-out." Bates No. 2051031944.

27 Memo to Mr JS Osmalov from WE Claflin. September 27, 1968 "Fallout from Filtrona CA Filters." Bates No. 1000870115

28 Memo to Mr RM Thomson from RG Snow. January 21, 1969. "Carbon particle fallout - flush fluted carbon filter." Bates No. 1001891145

29 Memo to Mr Paul Gauvin from VC Johnson. November 14, 1969. "Fallout of microporous filter material." Bates No. 1001890942.

30 Memo to Mr JW Hardin from VC Johnson. January 7, 1970. "Fallout of cigarette filter material." Bates No. 1000837582

31 Memo to Mr LF Meyer from JE Wickham. January 23, 1970. "Carbon particle fallout - Parliament cigarettes." Bates No. 1001883612

32 Memo to Mr Paul Gauvin from VC Johnson. April 14, 1970. "Particle fall-out." Bates No. 1000837620.

33 Memo to W Houck, Jr from Mr WE Claflin. December 7, 1970. "Multifilter fall-out - factory samples." Bates No. 100714807.

34 Memo to Mr JE Wickham from Nancy R Ryan. September 1, 1977. "Filter particle fallout." Bates No. 1000747815.

35 Memo to Mr JE Wickham from Nancy R Ryan. September 21, 1977. "Filter particle fallout." Bates No. 1000747938.

36 Memo to Mr JE Wickham from Nancy R Ryan. September 21, 1977. "Filter particle fallout." Bates No. 2022146643.

37 Memo to Mr Larry Stewart from Nancy R Ryan. November 29, 1977. "Filter particle fallout count." Bates No. 1000747812

38 Memo to Mr Larry Stewart from Nancy R Ryan. January 16, 1978. "Filter particle fallout." Bates No. 1000761599.

39 Memo to Mr J Myracle from Nancy R Ryan. January 16, 1978. "Filter particle fallout." Bates No. 1000761600

40 Memo to Carol Chase from Nancy R Ryan. Febuary 8, 1978. "Filter particle fallout count." Bates No. 1000761593.

41 Memo to Carol Chase from Nancy R Ryan. July 26, 1978. "Filter particle fallout count." Bates No. 1000761578.

42 Memo to Mr Joe Griffin from Nancy R Ryan. March 30, 1979. "Filter particle fallout count." Bates No. 1000767363

43 Memo to LF Meyer from JH Griffin, Jr, April 24, 1979. "Results of filter particle fallout tests performed on NWA cigarettes." Bates No. 1000767827.

44 Memo to Larry Stewart from Nancy R Ryan. May 16, 1979. "Filter particle fallout count." Bates No. 1000768463.

45 Memo to Mr Joe Griffin from Nancy R Ryan. May 22, 1979. "Filter particle fallout count." Bates No. 1000768527.

46 Memo to Mr Joe Griffin from Nancy R Ryan. July 11, 1979. "Filter particle fallout count." Bates No. 1000769461.

47 Memo to Mr Joe Griffin from Nancy R Ryan. September 20, 1979. "Filter particle fallout count." Bates No. 1000772357

48 Memo to - name expunged - from JG Nepomuceno. December 4 , 1981. "Project I C status report." Bates No. 2040037728.

49 Memo to Jose Nepomuceno from LR McCray. December 15, 1981. "Filter fallout." Bates No. 1000801671.
50 Memo to Judy Nash from Nancy R Ryan. Febuary 18, 1982. "Filter particle fallout." Bates No. 1000805035

51 Memo to Judy Nash from Nancy R Ryan. May 10, 1982. "Filter particle fallout count." Bates No. 1000808193.

52 Memo to Mr W Nichols from Don Laslie. June 14, 1982. "Project CT C-100: Celanese tow range extension device." Bates No. 2040044907.

53 Memo to Mr R Lambert from Nancy R Ryan. July 22, 1982. "Filter particle fallout count." Bates No. 2040037713

54 Memo to Rob Lambert from Nancy R Ryan. August 18, 1982. "Filter particle fallout count." Bates No. 1000811337.

55 Memo to Ms JA Nash from Nancy R Ryan. September 15, 1982. "Filter particle fallout." Bates No. 1000812957.

56 Memo to Ms Judy Nash from Nancy R Ryan. September 29, 1982 "Filter particle fallout." Bates No. 1000813239

57 Memo to Mr CF Vealey from Nancy R Ryan. October 15, 1982. "Filter particle fallout." Bates No. 1000814174.

58 Memo to Ms Mable Fleming from Nancy R Ryan. March 30, 1983. "Filter particle fallout." Bates No. 2040037709.

59 Memo to Ms Mable Fleming from Nancy R Ryan. May 4, 1983 "Filter particle fallout." Bates No. 2040037708.

60 Memo to Mr CF Vealey from Nancy R Ryan. June 23, 1983. "Filter particle fallout." Bates No. 1000822123.

61 Memo to Ms Mable Fleming from Nancy R Ryan. June 23, 1983. "Filter particle fallout." Bates No. 2040037700.

62 Memo to Mr CF Vealey from Nancy R Ryan. July 11, 1983. "Filter particle fallout." Bates No. 1000822772.

63 Memo to Ms Judy Nash from Nancy R Ryan. July 11, 1983. "Filter particle fallout." Bates No. 1000821974

64 Memo to Ms Mable Fleming from Nancy R Ryan. July 27, 1983 "Filter particle fallout." Bates No. 1000822669.

65 Memo to Willie Houck from Mable Fleming. August 5, 1983. "Filtrona multiple pneumatic filter (MPF) evaluation." Bates No. 2040037740-2040037744

66 Memo to Dr W Farone, Dr T Osdene, Dr R Selgiman, et al. ( $n=39$ recipients) from ML Fleming. August 19, 1983. "Filtrona multiple pneumatic filter (MPF) evaluation." Bates No. 2040037689-2040037698.

67 Memo to Mr CF Vealey from Nancy R Ryan. August 25, 1983. "Filte particle fallout." Bates No. 1000823733.

68 Memo to Ms Judy N Smith from Nancy R Ryan. October 12, 1983. "Filter particle fallout." Bates No. 2040037705.

69 Memo to Mr Murphy Sprinkel from Nancy R Ryan. Febuary 1, 1984 "Microscopic evaluation of filter particle fallout (silica gel)." Bates No. 2040037706

70 Memo to Mr EW Weston from Nancy R Ryan. February 15, 1984. "Filter particle fallout." Bates No. 2040037707.

71 Memo to Ms Judy N Smith from Nancy R Ryan. March 29, 1984 "Filter particle fallout." Bates No. 2040037687.

72 Memo to Ms Judy N Smith from Nancy R Ryan. April 9, 1984. "Filter particle fallout - Bridon Polypropylene." Bates No. 2040037688

73 Memo to Dr. James L. Charles from Murray D Rosenberg. May 11 1984. "TIS Monthly Summary - April 1984." Bates No. 2022225744-2022225754

74 Memo to Mr Walter Nichols from Nancy R Ryan. August 2, 1984. "Filter fiber fallout." Bates No. 2040024588.

75 Memo to Mr W Nichols from Nancy R Ryan. August 14, 1984. "Filter fiber fallout." Bates No. 2040015000

76 Memo to Dr TS Osdene from JE John. November 14, 1984. "Analysis of polypropylene dust." Bates No. 2040037729

77 Memo to Dr TS Osdene from Walt Nichols. November 21, 1984. "Particle fallout." Bates No. 2040037727.

78 Memo to JA Vaughan from TS Osdene. January 24, 1985. "FML materials testing." Bates No. $2040037730-2040037733$.

79 Ryan NR. Filter fiber fall-out. Method No. S-42. September 1985. Bates No. 2040020626-2040020629.

80 Ryan NR. Carbon particle fall-out. Method No. S-43. September 1985. Bates No. 2057064571-2057064574.

81 Memo to Ken Newman from Nancy Ryan. May 7, 1993. "Filter fiber fallout." Bates No. 2040014998-2040014999

82 Memo to Dr Kenneth S Houghton from Charity M Harris. January 12, 1995. "Background information on cigarette filter fibers release upon smoking." Bates No. $2040014985-2040014986$.

83 Memo to Dr NJ Jensen from Al Goldsmith. May 21, 1997. "Fallout of carbon particles or cellulose acetate fibers from filters." Bates No. 2060531292.

84 Memo to John Hearn from N Wermann and M Krauss. May 10, 1999. "Beta samples for filter fiber fall-out analysis." Bates No. $2063831140-2063831141$

85 CA is cellulose acetate, as disclosed in: "ABRVS/ACRON: a list of abbreviations and acronyms appearing in the: Monthly Progress ("Red Book") - Reports of the Research and Development Department. Written by Martha K Smith, and issued to T Osdene. June 12, 1987. Philip Morris, Inc. Bates No. $2001200179-200120204$

86 Ryan NR. Denier per filament of cigarette fibers. Method No. F-13. Jan. 1986. Bates No. 2501259267-2501259269.

87 Ryan NR. Paraffin embedding and preparation of cross structures of materials for microscopic examination. Method No. F-12. January 1986 Bates No. 2501270043-2501270048.

88 Project report from Dr JF Whidby (manager), April 1, 1981 "Biomaterials Science Division." Bates No. 1000803442

89 Correspondence to John Pauly from William Farone. November 17 2001. "Fall-out" Manuscript - Citation of Dr Farone. 
90 Philip Morris USA. Confidential - "Notice of Active Records Disposal." Correspondence to Nancy R Ryan (cigarette testing). Febuary 1, 1994. Bates No. $2054906113-2054906114$.

91 Memo to RADOC from Mace, VC. March 3, 1965. "Review of cigarette product development program: improved P. M. filter cigarette, interim triple plug cigarette, revised M-III using long par. Bates No. 1000866768-1000866776.

92 Kozlowski LT, O'Connor R. Cigarette filter ventilation is a defective design because of misleading taste, bigger puffs, and blocked vents. Tobacco Control 2002;11 (suppl I):i40-50.

93 Hastrup JL, Cummings KM, Swedrock T, et al. Consumers' knowledge and beliefs about the safety of cigarette filters. Tobacco Control $2001 ; 10: 84-6$

94 Correspondence to Dr John Pauly, Roswell Park Cancer Institute, from Chris Coggins, PhD, DABT, RJ Reynolds Tobacco Company. January 5, 1993. Bates No. 2063605470-2063605475.

95 Correspondence to Chris (Coggins), R Reynolds Tobacco Company, from Dan Heck. January 5, 1993. Bates No. 87626406.

96 Langer AM, Nolan RP, Bowes DR, et al. Inorganic particles found in cigarette tobacco, cigarette ash, and cigarette smoke. In: Wehner AP, Felton DL, eds. Biological interaction of inhaled mineral fibers and cigarette smoke. Columbus, Ohio: Battelle Press, 1988:421-40.

97 Streck RJ, Jezewski HM, Rodriguez MI, et al. Identification of cigarette filter fibers in the lungs of patients with cancer. May 19-22, 1993. Orlando, Florida. American Association for Cancer Research 1993;34:264[abstract 1571]

98 Pauly JL, Allaart HA, Rodriguez Ml, et al. Fibers released from cigarette filters: an additional health risk to the smoker? Cancer Research 1995:55:253-8

99 Borowicz JS, Streck RJ, Pauly JL. Contamination of cigarette filters with cellulose acetate fibers and particles documented in studies of adult smokers. Proceedings of the Annual Meeting of the American Association for Cancer Research, New Orleans, March 28-April 1, 1998;39:336 [abstract 2293].

100 Streck RJ, Stegmeier SJ, Mayer AG, et al. Cigarettes with compartment-type charcoal filters release carbon granules, cellulose acetate filter fibers, and other filter elements during smoking. April 12 16, 1997. Washington DC: American Association for Cancer Research, 1997; 38:371 [abstract 2486]

101 Pauly JL, Stegmeier SJ, Mayer AG, et al. Release of carbon granules from cigarettes with charcoal filters. Tobacco Control 1997;6:33-40.

102 Pauly JL, Lee JL, Hurley EL, et al. Glass fiber contamination of cigarette filters: an additional health risk to the smoker? Cancer Epidem Biomark Prev 1998:7:967-9.

103 Pauly J, Streck RJ, Cummings KM. U.S. patents shed light on Eclipse and future cigarettes. Tobacco Control 1995;4:261-5.

104 Longo WE, Rigler MW, Slade J. Crocidolite asbestos fibers in smoke from original Kent cigarettes. Cancer Res 1995;55:2232-5.

105 Pauly JL, Cummings KM, Streck RJ. The third phase of mainstream cigarette smoke identified as fibers and particles released from cigarette filters. 11th World Congress on Tobacco or Health, Chicago, Illinois, August 6-1 1, 2000. Vol. III, page 757 [abstract PO405]

106 Farr WK, Revere A. Examination of whole cigarette smoke by light and electron microscopy. New York: Life Extension Foundation, 1958.

107 Memo to Dr RN DuPuis from LS Harrow. Special report from the Food and Drug Research Laboratories. June 25, 1959. Bates No. 1001602481 .
108 Report. From the Food and Drug Research Laboratories, Inc. Comparison of filter-tipped cigarettes with respect to particulate matter found in the filters. Bates No. 1001602482 to 1001602503.

109 Memo to Ms Jan Jones from Page Callahan. Consumer Research Group. July 1, 1988. Premier - concept and product reactions. (Appendix B). Philip Morris. USA, Richmond, Virginia. State of Connecticut $v$ tobacco companies. Bates No. CV96007214S.

110 Wireback T, Catanoso J. Smoker's lungs could hold bits of tobacco filters. Greensboro News and Record. December 13, 1992: A1 and A6.

111 Pauly JL, Jezewski HM, Rodriguez MI, et al. Human lung tumor immunology: Cigarette filter fibers identified in the lungs of patients with cancer. May 21-25, 1993. Denver, Colorado. Joint Meeting of the American Association of Immunology and Clinical Immunology Society. Vol. 150, No. 8, part II:309A [abstract 1770].

112 Letter to Lockman from Cubbage. PM's "lost" documents. September 23, 1996.

113 Cummings KM, Morely C, Hyland A. Failed promises of the cigarette industry and its effect on consumers misperceptions about the health risks of smoking. Tobacco Control 2002;11 (suppl I):i1 10-17.

114 Memo to DH Wakeman et al from RN Thomson and LF Meyer. (N $=15$ ). January 20, 1964. Outline of carbon filter investigations at the research center, 1958 through 1963. Bates No. 2024084742-2024084773

115 Memo to E Wakeham from Mr Hugh Cullman. January 12, 1962 Your memo of January 9, 1962 in re coughing by dual Tareyton smokers. Bates No. 1001882139.

116 Memo to AJ Stevens from AW Spears (Lorillard). Febuary 2, 1993. "Dr Pauly of Roswell Park." Bates No. 87507883.

117 Roper W, Murray A. 9852 - evidence of cellulose acetate fibre release from cigarette filters during smoking, Reemtsma, CORESTA. 1995 Smoke and Technology Meeting, Vienna, Austria. [abstract. ST18]

118 SRRC, Social Science Research Council of the University of York; Goldsmiths College. Meeting, June 15, 1995. 1. Cigarette filter fibers; 2. Sensory properties of nicotine; 3 . RASS publication. Bates No. 2029400041-2029400044

119 Pauly JL, Stegmeier SJ, Allaart HA, et al. Inhaled cellulosic and plastic fibers found in human lung tissue. Cancer Epidem Biomark Prev 1998;7:419-28.

120 McCormack AD. Investigation of fibre and particle release from cigarette filters. Paper presented at the meeting of the Smoke and Technology Groups. Centre de co-opération pour les recherches scientifiques relatives au tabac (CORESTA), Brighton, England October 11-15, 1998:296-304.

121 Collazo H, Drow WA, Gardner L, et al. Application of inertial impactors for the measurement of aerodynamic diameters of cellulose acetate fibers. Paper presented at the meeting of the Smoke and Technology Groups. Centre de co-opération pour les recherches scientifiques relatives au tabac (CORESTA), Innsbruck, Austria. September 5-9, 1999. Abstract ST15.

122 Collazo H, Crow WA, Gardner L, et al. Development of inertial impactors for measurement of aerodynamic diameters of man-made organic fibers. Eastman Chemical Co, Dept of Mechanical Engineering, University of Minnesota, CORESTA. 1999. Meeting of the smoke and technology study group, September 5 - 9, Innsbruck, Austria. Abstract ST 14. 